\title{
Identity and Integration in the Asia-Pacific Region through the Prism of Tourism: Taiwan \& Japan
}

\author{
Lin Fan, Lavanchawee Sujarittanonta ${ }^{\star}$ and Arunee Lertkornkitja ${ }^{\star}$
}

\begin{abstract}
This is an attempt to understand identity and integration in the Asia-Pacific region through the prism of tourism. Our study begins with a review of fields associated to travelling from geography to economics and literature -and applies some important conclusions to the current dynamics of the Asian-Pacific zone. It also includes a thorough quantitative analysis, complete with t-statistics and ANOVA to test two main hypotheses. Our findings are astounding, because they elaborate on the mysterious nature of international flows, from capital to individuals to commodities. We deliver insightful conclusions on race, gender and sexualities, as well as the dynamics of integration within a comparative study of Taiwan and Japan. These conclusions rest on a total of 354 questionnaires that were completed, returned and analysed thanks to a research grant. It is hoped that this study of tourism will be found to be enlightening in the context of contemporary dynamics in the Asia-Pacific region.
\end{abstract}

Keywords: identity, integration, Japan, Taiwan, tourism

\section{Introduction}

It is arguable whether globalization leads to standardization and loss of identity or helps to bring about intensification of one's own uniqueness in order to resist the dilution and assimilation of one's own culture. This dilemma has been addressed by various researchers in tourism in particular, because tourism imports elements of foreign cultures and exports one's own culture elsewhere. The literature also addresses the "sustainability" of intercultural tourism (e.g. van Rekom \& Go, 2006) and how the effort to sustain one's cultural uniqueness leads to "heritagization" in tourism development (Bujdoso et al., 2015). To create regional identity, regionalism has also become another outcome from the drive for cultural sustainability, even for islands as in the case of a study by Sani and Mahasti (2012) on Iranian tourism.

* Dr. Lin Fan is a faculty member at the Department of Entertainment Management, I-Shou University International College, Kaohsiung, Taiwan.

* Dr. Lavanchawee Sujarittanonta is Assistant Professor, Institute of Public Administration and Governance (IPAG), Shinawatra University, Thailand.

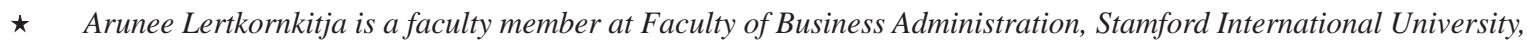
Bangkok, Thailand. 
Research on tourist market segmentation that addresses multi-cultural tourists usually emphasizes not only how each cultural group perceives hospitality, tourism and travel services but, also, age groups. For example, it was found that in making travel purchase decisions, elderly tourists consider many different aspects of their trip compared to tourists in other age ranges. Based on the different weights given by tourists to various tour attributes, Kim, Wei and Ruys (2003) found that tourists to Western Australia can be categorized into different groups, namely, senior groups, active learners and relaxed family bodies.

\section{Literature Review}

\subsection{Approaches to and Foci of Cross-Cultural Management Research}

The six approaches to cross-cultural management research, adapted from Adler (1983) by Capaldo, Pianoa and Cerrato (2013) are described below. They have been integrated and adapted for this study. Adler (1983) proposed that there are six approaches to researching cross-cultural management issues: parochial, ethnocentric, polycentric, comparative, geocentric and synergistic. For each approach, assumptions are discussed concerning the similarity and difference across cultures.

1. Parochial Approach: Studies are designed and conducted in one culture by researchers from that culture (e.g. studies of the USA conducted by people from the USA). Parochial culture means viewing the world solely through one's own eyes and mind's perception. A culture with a parochial perception does not recognize another culture's different ways of thinking, perceiving and proceeding. Organizations in which managers ignore the potential impact of cultural diversity are labelled "parochial" by Adler (2002).
2. Ethnocentric Approach: Studies originally designed and conducted in one culture by researchers from that culture are replicated in a second culture. Ethnocentric managers recognise diversity but only as a source of problems. An "ethnocentric" organization (ibid.) assumes that cultural diversity among employees has clear disadvantages with no advantages. The ethnocentric organization seeks to minimize the sources and impacts of cultural diversity by selecting a monocultural workforce and forcing diverse others to assimilate the values, attitudes and behaviours of the predominant group.

3. Polycentric Approach: Individual domestic studies conducted in various countries around the world in the search for that which is specific in a particular culture).

4. Comparative Approach: Studies are designed to identify the similarities and differences across two or more cultures and thus distinguish between those aspects of organizational theory which are truly universal and those which are culturally specific.

5. Geocentric Approach: Studies focus on organizations operating in more than one culture, so as to identify similarities among cultures which will allow multinational organizations to have unified policies for their worldwide operations.

6. Synergistic Approach: Studies explore crosscultural interaction and the positive uses of similarities and differences in creating both universal and culturally specific patterns of management. The focus is not on understanding the patterns of relationships so much as the theories which apply when people from more than one culture interact within a work setting, typically within multinational and transnational organizations. 
2.2. Identity and Integration Challenges: Language

Language is also another consideration in tourism strategies, for example in Japanese and Chinese cultures, which aim to preserve strong identities. This foreign language inadequacy (i.e. failures in communication) extends not only to English but, also, to Japanese and Chinese languages. Both Japanese and Chinese tourists prefer to communicate in their own language rather than using English. This can lead to communication difficulties (Fukahori et al., 2011). As a result, tourism service providers have to hire personnel who can speak Japanese and Chinese to a suitable level. The language situation may be a clue that suggests the limitation of tourists with strong cultural identities in contributing to the economy of the tourist destination. Even Las Vegas, which has exported the model of casino gaming to Asia, is now thinking of including Mandarin Chinese as its second official language (Galaviz, 2012). It was also found that, for most service providers, in countries with strong cultural identities and unique national language, both managers and personnel also admit that they need to improve their foreign language skills and learn more than just basic English. Tourists today also tend to spend more time having long conversations with service personnel, requiring more interpersonal skills in conversation beyond standard transactional verbal communications.

\subsection{Comparing China and Japan along Hofstede's 6-D Model}

China and Japan's culture are different in many dimensions. Japan has a notably higher ranking in individualism, masculinity, uncertainty avoidance and indulgence, while China ranked very high in power distance with a score of 80 , meaning that the inequalities amongst people are considered acceptable. Individuals are influenced by formal authority and sanctions and are in general optimistic about people's capacity for leadership and initiative. Japan, with a score of 54 in this case, is borderline hierarchical, in which all the decisions must be confirmed by each hierarchical layer and finally by the top management. Japan has been a meritocratic society, as can be seen in the Japanese education system which is based on the meritocratic basis that everybody is born equal and a person can get ahead and achieve all goals through working sufficiently hard.

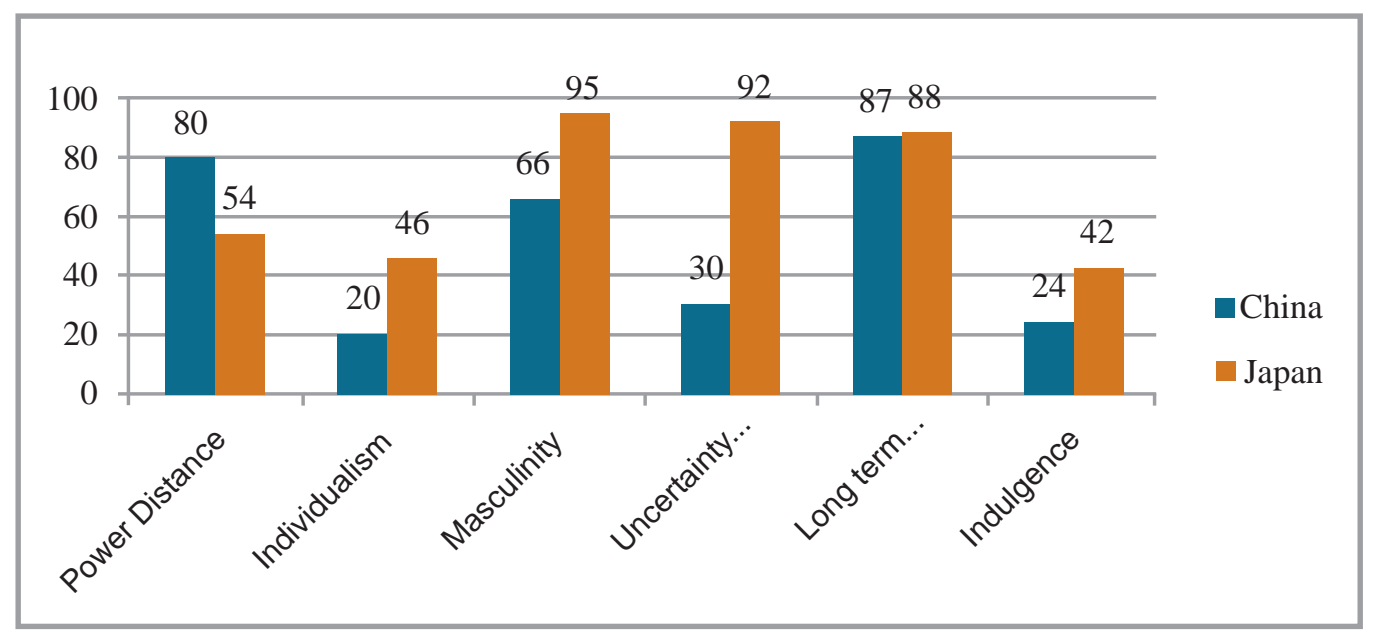

Figure 1: Randings of Japan and China According to Hofstedian Cultural

Framework; source: Hofstede, n.d. 
China and Japan show the characteristic of being a collectivistic society, with scores of 20 and 46 respectively. People tend to act in the interests of the group rather than for themselves as individuals. Japanese society does not have the extended family system which forms the basis of more collectivistic societies and this is different from China. Furthermore, Japanese are famous for their loyalty to their companies. However, company loyalty is something which people have chosen for themselves, which is an individualist thing to do. It can be said that in more collectivistic cultures people are loyal to their inner group by birth (i.e. kinship groups), such as their extended family and local community. Japanese are experienced as collectivistic by Western standards and experienced as individualistic by Asian standards. Japanese are more private and reserved than most other Asians.

Japanese is one of the most masculine societies in the world, with a score of 95 compared to China at 66. Both are success oriented and driven societies and have people who will sacrifice family and leisure priorities for work. With this very high score, Japanese workaholism is an expression of the masculinity level. It is still hard for women to climb up the corporate ladders in Japan, partly because of the masculine norm of hard and long working hours. However, in combination with Japanese's mild collectivism, assertiveness and competition within a group are hardly seen but there is severe competition between groups. Furthermore, at 92, Japan is one of the most uncertainty avoiding countries in the world. Japanese learn to prepare themselves for not only any uncertain situation from the constant threat of natural disasters but also from other aspects of society. In the corporate world, Japanese tend to spend a lot of time and effort in feasibility studies and calculate all the risk factors before any project can commence. This is the reason why changes are so difficult to realise in Japan. By contrast, with a score of 30, Chinese are more comfortable with ambiguity. In Chinese society, then, adherence to laws and rules may be flexible to suit an actual situation and pragmatism is a fact of life.

At 87 and 88 respectively, China and Japan have the highest long term orientation oriented societies. They encourage thrift and devote effort to a modern form of education as a way to prepare for the future. In corporate Japan, a long term orientation can be clearly seen in the constantly high rate of investment in $R \& D$ even in economically difficult times, higher own capital rate, priority placed on steady growth of market share rather than to a quarterly profit and so on. These factors all contribute to the durability of the companies. The idea behind it is that the companies are not here to make money every quarter for the shareholders but, instead, to serve stakeholders and society at large for many generations to come (e.g. Matsuhista) (Hofstede, n.d.).

Chinese and Japanese societies are generally constrained and do not place much emphasis on leisure time while controlling the gratification of their desires. People with this orientation have the perception that their actions are constrained by social norms and feel that indulging themselves is somewhat wrong. However, even though both countries have this characteristic, Japanese, at 42, have a lower tendency to cynicism and pessimism than Chinese, at 24 for the indulgence dimension.

\subsection{Tourism characteristics of Taiwan and Japan}

Taiwan encourages tourism as a source of income and a means of displaying Chinese culture. Taiwan's tourism industry grew from 15,000 visitors in 1956 to over 2,000,000 per year in the 1990s. Japan is the main country of origin 
of tourists, representing $36 \%$ of visitors, followed by the USA (13.5\%) and Europe (7.3\%). Mainlanders also visit Taiwan via Hong Kong. Visitor expenditures in Taiwan grew from US\$527 million in 1977 to US\$3.4 billion in 1997, which is an increase of $85 \%$ (Hudman \& Jackson 2003: 411). In 1994, Taiwan had the same number of visitor arrivals as India (over two million). Taiwan's largest market is AsiaPacific travellers, who account for over $70 \%$ of the overall market. Taiwan's inbound tourism market has been heavily dependent on just six countries, which accounted for $81 \%$ of the region's visitors from 1977 to 1994. Consequently, Taiwan's attractiveness has expanded over time. In 1977, only $15 \%$ of visitors to Taiwan came from other than the six main countries but, by 1994, those other countries accounted for $25 \%$ of visitors. The number of Japanese tourists increased from 563,000 in 1977 to 824,000 in 1994 but, based on percentage, the total visitors actually decreased from $51 \%$ of the market in 1977 to $39 \%$ in 1994. Growth in Taiwan's inbound market has been slow for the past decades. From 1997 to 1999, inbound arrivals have remained steady at 2.4 million. Reasons for the low growth include:

1. Strengthening of Taiwan's currency in the late 1980s.

2. A shortage of new or strong international tourist and leisure attractions

3. Tourist attractions not being readily accessible.

4. Difficulties in obtaining appropriate travel documents.

5. A lack of direct air links between Taiwan and major tourist-generating countries. (Eagles, Bowman \& Tao 2001: 20-22).

The population of Taiwan was about 22.75 million and GDP was US\$290 billion in 2004.
Taiwan had diplomatic ties with only 26 countries in 2005. It is necessary to propose measures for the Taiwanese in terms of hardware and software. A lot of Taiwanese visit cities (Oyabu et al., 2008: 73). In 1979, Taiwan allowed its citizens to travel abroad, except for men between the ages of 16-30 who had not completed their military service. Each traveller could take two trips per year. Travel to China was still banned until November, 1987. On July 1st, 1988, the age ceiling on males was reduced to 26 years from 30 years and the tourist exit and entry tax was reduced by half from NT $\$ 4,000$ to NT $\$ 2,000$. Consequently, Taiwanese travel more than tripled from 485,000 to 1.6 million trips between 1980 and 1988. By 1991, nearly half of all trips were holiday trips. Taiwan is currently encouraging its citizens to travel abroad because it sees travel as a way to improve its image and to foster better relations with the rest of the world. In 1999, Taiwan citizens took nearly 6.6 million overseas trips and the number has continued to grow (Mak 2004: 103). Meanwhile, Japanese citizens were not allowed to go abroad until 1964. By 1978, all foreign exchange controls were abolished. The liberalization of foreign tourist travel combined with the introduction of the jumbo jet in 1970 enabled the mass marketing of prepaid package tours. The subsequent explosion in Japanese overseas travel was a very prominent phenomenon. Until the first global energy crisis in 1973, Japanese outbound travel increased at an average annual rate of $40 \%$, rising from 160,000 in 1965 to 2.3 million in 1973. In 1965, only $28 \%$ of Japanese overseas trips were for pleasure. Today, nearly two-thirds of all Japanese trips abroad are for sightseeing: in other words, for pleasure not business. Of course business trips remain important but they tend not to be so enjoyable for those who take them. The Japanese government took steps to encourage its residents to go on foreign trips to help solve a large and growing trade imbalance between 
Japan and the rest of the world. For example, in 1987, the government announced the "Ten Million Program" to increase the number of Japanese tourists from 5.5 million in 1986 to a staggering 10 million in 1991. That target was achieved one year ahead of schedule (ibid.: 104). There was considerable growth in tourism arrivals from 1987 to 1992 in Japan, reaching 3.53 million in 1991 (an increase of 50\%). The main stimulus of growth was the Asian market (up 74.6\%), in particular South Korea (24.4\%), Taiwan (18.6\%), the USA (15.4\%) and Hong Kong (4.4\%). By 1995 , however, arrival numbers were lower than they had been since 1990. The major reasons for the decline were the devastating earthquake in Kobe and the strong Yen. The average length of stay in Japan fell from 14.9 days in 1988 to 9.4 days in 1995 . Tourism officials introduced a new strategy designed to revive interest in the country and targeted a doubling of visitors to 7 million by 2005. With significant increases of Asian visitors (especially from Korea), there has developed a shortage of qualified guides and interpreters. The Japan National Tourist Organization (JNTO) has identified three areas to develop tourism:

1. Expand its activities in the Asian market.

2. Encourage efforts to attract visitors to Japan's regional areas.

3. Step up the promotion of Japan as a convention and exhibition destination.

Japan was Hong Kong's largest market from 1971 until 1990, when Taiwan overtook Japan. Hong Kong has benefited from the sudden surge of outbound traffic from Taiwan, which was a result of rapid economic growth and the easing of travel restrictions. It was not until October 1987 that Taiwanese citizens were allowed to travel to China via a third country such as Hong Kong. In 1994, China became Hong Kong's largest market. Even though Japan is no longer the primary market, it is still very important financially, because Japanese travellers stay a little longer than Taiwanese travellers (2.9 days compared to 2.2 on average) and spend more. Taiwan is considered to be both a pleasure destination and a business destination in the Asia-Pacific and rapid growth of the industry will continue (Eagles, Bowman \& Tao 2001: 20-22). The number of foreign tourists visiting Japan is currently increasing to about 500700,000 per month. This achievement was largely dependent on the Visit Japan Campaign (VJC), proposed by the government in 2003. Korean tourists are most populous out of foreign visitors to Japan. The number was 1.75 million in 2005 . Taiwanese visitors represent about 1.3 million (19\%) and American visitors 0.83 million $(12.3 \%)$. The rate of Taiwanese inbound visits went up $17 \%$ in 2005 . This means that the Taiwan-Japan tourism exchange is becoming more important. The ratio of Taiwanese tourists that visited the Hokuriku district was the largest out of all foreign travellers in 2005. The Hokuriku district includes Ishikawa, Toyama and the northern part of Gifu prefecture (Takayama, Hida cities and Shirakawa village). Tourism campaigns were implemented in Taiwan by the Takayama and Ishikawa policies in 2004 and 2005. However, in the Hukuriku district, tourism has decreased remarkably since 1992 . Other instances of decline are also expected if tourism destinations are not able to reinvent themselves successfully.

\subsection{Synthesis: Tourism as a Reflection of Japan-Taiwan Relations}

In Taiwan, the emergence of local museums in the 1990s was seen as a result of the politics of local identity. The local governments that arose within the new, interactive political network played an important role in promoting locations through cultural tourism, such as museums, cultural festivals and the production of local artefacts. Along with strategic support from the 
central government and new trends in leisure and tourism, the idea of local specialties was promoted. For example, cultural festivals that emerged to promote the idea of local agricultural products, crafts and heritage sites were held by regional governments in the 1990s and sponsored by the central government as a part of the national culture programme. Within this historical context, the recollection of local memories has become intertwined with Taiwanese identity. As a result of the museum and heritage boom, Japanese colonial sites have received greater attention than ever before. Taiwan's palimpsests of colonial monuments are often seen during transitions of ruling power. The most apparent examples have been the removal of Japanese remains by the Kuomintang (KMT) during the post-war era. The KMT interpreted Japanese remains as symbols of the enemy country that had invaded China during the period of Japanese imperialism. This anti-Japanese attitude changed at the transition of identity narratives. Over the last two decades, a pro-colonial attitude has emerged in the field of conservation, coinciding with prominent research on Taiwanese history. Increasingly Japanese remains have been nominated as sites of national or regional heritage (Chiang, 2010).

In 2010, no less than 2.3 million Taiwanese and Japanese travelled between their respective countries. In 2012, this figure reached 3 million. In order to make travel more convenient, an international driver's license was introduced at the request of the Governor of Hokkaido, where Taiwanese represent the largest group of tourists. Taiwan took the initiative to introduce a working holiday system with Japan in June, 2009. Working holidays enable young people of both sides to study language and work legally in the host country for a limited period of time. In December, 2009, the Taipei Economic and Cultural Representative Office opened an office in Sapporo. In August, 2011 the Commissioner of the Japan Tourism Agency visited Taiwan for the first time. Since July, 2012 Taiwanese tourists and have been authorized to write "Taiwan" instead of "China" on the immigration form when they enter Japan. Taiwan has invited more Japanese visitors to meet President $\mathrm{Ma}$ and designated 2009 as "Taiwan-Japan special partnership year." Japan also showed a stronger interest in cultural diplomacy with Taiwan. An achievement in promoting cultural exchange was the enactment in March 2011 of a law enabling the launch of a National Palace Museum exhibition in Japan. After more than five years of political and legal discussions, the simultaneous exhibition in Japan of works from the Taipei and Beijing National Palace Museums was made possible. The first exhibition took place in 2014 in Tokyo and Fukuoka. It was extremely successful. Since then, five Taiwanese universities, including Taipei's National Chengchi University, have launched new centres in modern Japan studies (Sahashi 2014: 235-6). As a result, it is extremely important to design a policy that increases tourism with a view to internationalization (Oyabu et al., 2008: 74). The Taiwanese have a relative sense of closeness to Japanese culture and would like to encourage them to visit again and again. They can see different temples, different mountains and different cars on the motorway. The Japanese are encouraged to visit and not be concerned by the ghosts of the past, which Taiwanese are putting behind them. They have also taken steps to provide interesting, attractive and affordable tourist destinations.

Taiwan-Japanese relations were briefly disrupted by a 2008 collision between a Taiwan fishing boat and a Japanese ship near the contested Diaoyu/Senkaku islands. In May 2009, however, another major issue erupted when the Japanese ambassador to Taipei, Sairo Masaki, said that Taiwan's status was still unresolved. Although Saito had correctly stated his government's 
position, the KMT administration reacted negatively, stating that he had made inappropriate remarks and demanding that he be declared persona non grata. Saito apologized, even as those Taiwanese who agreed with him delivered flowers and supportive notes to the Interchange Association. Salto stayed on but, after being denied access to Taiwan's top-level officials, he resigned, citing personal reasons. There have also been some more positive developments in Japan-Taiwan relations during the $\mathrm{Ma}$ administration. In June 2009, for example, regular flights between Taipei's Songshan and Tokyo's Haneda airports began service (Dreyer 2012). The researchers took these flights on a couple of occasions to observe the behaviour of tourists in the aircraft and when landing and claiming their luggage in both airports. It was found that most Taiwanese were as excited about their trip to Japan as the Japanese were to visit Taiwan. Young Japanese in particular, were looking forward to tasting Taiwanese delicacies. Teenaged Taiwanese seemed interested in cosplay culture and Tokyo bananas (a very popular form of confectionery). This excitement was made possible through the new visa system instituted in 2009, which Ma had designated "Year to Foster Special Partnership between Taiwan and Japan." The partnership allowed 18-30 year olds in each country to spend up to a year in the other. In the wake of the March 2011 natural disaster in Tohoku, several Japanese companies including Sony, Mitsubishi and TDK expressed interest in investing in electronic components in Taiwan. This was considered to be excellent economic news, especially because the government established a Japan office to study how to promote Taiwan as a back-up manufacturing base for Japanese companies in their efforts to cooperate with their Taiwanese partners. President Ma was instrumental in reducing crossstrait tension, though in such a way that it caused his opposition and conservatives in Japan to believe that Taiwan's sovereignty was being eroded through increased ties with China. JapanTaiwan economic ties remained strong: Japan is Taiwan's second largest trading partner, with Taiwan Japan's fifth largest source of trade. However, China is Japan's largest trading partner. Wu Mali created an artistic installation Formosa Club:The Magic Power of Taiwan's Fortune in 1998 in which she retraces Taiwanese history from the sixteenth century on from a sexual perspective. In this work, $\mathrm{Wu}$ inscribes the masculine metaphor of the colonized nation as the raped woman into a feminist critique of the patriarchal forces that have depended upon Taiwan women's sexual labour for political and economic gains. The grand narratives of the nation hide behind them the blood and sweat of the most unspeakable form of labour. Recuperating this history thus exposes the hypocrisy of the national narratives of Taiwan's success. In this strange work, the entire island of Taiwan is portrayed as a sex club, serving the Japanese soldiers as "comfort women" during the Pacific War, the American GIs during the Vietnam War, the Japanese tourists during the heyday of Japan's "sex tourism" to Taiwan, if not local clientele of all classes (Shih 2007: 177). Sometimes, it must be admitted, the work appears to be obscene if not disgusting. This kind of pornography might be treated by some as trash but, in the serious historical context that is provided, scholars have not just tolerated it but taken it seriously. However, there is a danger of the trivialization of the sexual act. Making love is beautiful and full of meaning but what is more important in the act of making love is the materiality of our beings -the skin, the sweat, the saliva, the hair, the excretions, even the sex toys. More important even than that is the holy trinity of colonialist, nationalist and capitalist expansion that depends upon the dispensing of surplus male libido in and over the exploited bodies of local women. 


\section{Methodology and Research Findings}

The research reported on in this paper is based on a questionnaire survey of Japanese and Taiwanese respondents using a research instrument designed by the research team. A total of 354 completed questionnaires were received and analysed for this paper. Taiwanese and Japanese tourists were segmented into attraction assets according to coefficients of attraction, fascination and sightseeing desirability. These representational assets were subsequently explored through factorial ANOVA and one-way ANOVA tests. Significant differences were located in both sightseeing and desirability judgements. Analysis based on focus groups and personal interviews divided tourists into various psychographic segments, labelled according to relevant lifestyle dimension: sightseers (SS), naïve spectators (NS), food lovers (FL) and lost souls (LS). Respondents who did not conform to this schema were classified as other $(\mathrm{O})$. The attitude of respondents to these different groups was addressed through the questionnaire survey.

Typically, the SS and NS attached significantly more value to religious sites and Taiwanese customs ( $\mathrm{p}=0.012$ and 0.005 , respectively). NS and SS revealed significantly more desire for developing landscape sites, religious sites and traditional yards as tourist attractions than their counterpart FL and LS. In terms of Japanese daily life and customs, SS showed significantly greater interest in developing these assets compared with other groups, especially FL and to a lesser extent the NS. For the development of Taiwanese customs, LS revealed significantly less desire to turn them into tourism attractions than the other groups who shared a similar level of interest. During the outstanding focus groups we conducted, images of tourists, their motivations for travelling and the classification of tourist groups were analysed. The generating areas of the tourists were the most recognizable grouping criteria. In the questionnaire-based survey, as many as 241 respondents out of 354 chose $\mathrm{O}$ instead of any tourist groups identified in the focus groups. According to the face-toface conversation just after the questionnaire, those who chose $\mathrm{O}$ did not care about the origin of tourists. For them, all tourists were guests and should be greeted with care and excitement. This attitude concurs with Confucian and Shinto values. For the rest of the 113 respondents who specified their preferred tourist groups, descriptive analysis was conducted. Interestingly, it was determined that the preference patterns for the tourist attraction assets were similar. The following results were obtained:

1. Tourists from Taiwan and Japan were the most preferred.

2. Tourists from both inland China and coastal China were also liked but not as much as the Taiwanese and the Japanese.

3. Most tourists from either Taiwan or Japan respected culture, religious beliefs and traffic rules.

4. A dislike of Caucasians was identified in a minority of Japanese and Taiwanese tourists, who saw white Americans as "arrogant Yankees" or "control freaks" and black Americans as "fake rappers" and "ghetto fashion makers."

Such preferences were then explored and compared by cross-tabulation analysis using the Chi-squared test. Significant differences were found in the preferred tourist groups of Japanese inns and Taiwanese motels ( $\mathrm{F}=24.95$, 2-tailed $\mathrm{P}=0.015)$. SS are the group who most welcomed tourists from central Taiwan. FL, who argued for the control of tourist volume, showed significantly more preferences for non-Asian tourists. Most tourists groups were relatively evenly distributed among tourists from Japan and tourists from Taiwan. 


\section{Conclusion \& Suggestions for Further Research}

This paper adopted a forward-looking perspective with regard to tourism as a powerful attraction asset. A framework using social representations theory has provided an enlightening view that shaped the argument via an emic approach. Tourism is not an undifferentiated phenomenon. Rather, it means many different things to different people. For SS, tourism seems a good livelihood choice and they will seize this livelihood strategy when suitable opportunities arise. NS noticed the benefits brought by tourism and were positive about tourism development in the future. However, they were more enthusiastic about working in other areas than the tourism industry. The third group, FL, advocated quality tourism and hoped to control the volume of tourists. The final sub-group, LS, were current beneficiaries of tourism development - and as such, positive about tourism in all aspects. In their eyes, tourism was a panacea for both personal and community wellbeing. It should be stressed that it is claimed that tourism acts like a form of diversification, no matter whether it is measured at its current stage or seen in the future. This kind of representation is supportive of previous studies that declare the strategic importance of sustainability and diversification.

The interview data suggests that, like all forms of tourism, the economic benefits to be derived from having tourists staying longer are not always necessarily positive. Taiwan's tourism industry enjoyed a very high number of Japanese visitors until a few years ago, when the growth rate slowed and eventually declined. This decline was caused by several factors such as the high appreciation of the NT\$, inconvenient visa application procedures, limited airline seats, rising public disorder and competition from other Asian countries. Senior Japanese tourists (50 years and older) have become extremely desirable, because they admire Chinese culture, cuisine, landscapes and sunny weather. So, even if Taiwan has somewhat limited potential in terms of tourist growth, it can keep up promising revenue from tourism. Consequently, a longitudinal multicultural study would help to shed light on how service providers adjust to foreign long-stay tourists. It would also be interesting to find out how the socio-cultural interaction plays out the long term, with increasing numbers of Taiwanese-Chinese and Japanese seniors living and interacting in foreign cultural spaces, how the host destination's public would change their perceptions and their traditional cultural values towards the Chinese and Japanese (Chen 1992).

\section{References}

Adler, N.J. (2002). International Dimensions of Organizational Behavior, Cincinnati, OH: SouthWestern.

Adler, N.J. (1983). "A Typology of Management Studies Involving Culture," Journal of International Business Studies, 14(2), 29-47.

Bujdosó, Z., Tözsér, D.L., Kovács, A., Major-Kathi, G., Uakhitova, V., Katona, P. and Vasvári, M. (2015). "Basis of Heritagization and Cultural Tourism Development", Procedia -Social and Behavioral Sciences, 188, 307-15.

Capaldo, A., Della Piana, B. and Cerrato, D. (2013). "Toward an Organizing Framework for CrossCultural Research in Management Studies," paper presented at the Italian Academy of Management (Lecce), available at: http://www.aidea2013.it/docs/200_aidea2013_ma nagement-organization.pdf.

Chen, N.-C. (1992). Senior Japanese Tourists to Taiwan and their Marketing Potential: A Case Study, unpublished thesis, Rochester, NY: Rochester Institute of Technology.

Chiang, M.-C. (2010). "The Hallway of Memory: A Case Study on the Diversified Interpretation of Cultural Heritage in Taiwan," in Heylen, A. and Sommers, S. (eds.), Becoming Taiwan: From Colonialism to Democracy, Wiesbaden: Harrassowitz Verlag, 117-132. 
Dreyer, J.T. (2012). "Japan's View on Cross-Strait Developments," in Chow, P.C.Y., (ed.), National Identity and Economic Interest: Taiwan's Competing Options and their Implications for Regional Stability, New York, NY: Palgrave Macmillan, 283-298.

Eagles, P.F., Bowman, J. Margaret, E. and Tao, T.C.-H. (2001). Guidelines for Tourism in Parks and Protected Areas of East Asia, Gland and Cambridge: IUCN.

Fukahori, H., Baba, Y., Hioki, F. and Monkong, S. (2011). "Healthcare Services for Japanese Elderly LongStaying in Thailand from the Perspective of the Patient and Healthcare Providers: A Survey Study," Archives of Gerontology, 53(2), 168-73.

Galaviz, J. (2012). "The Boomerang Effect: Asia's Casino Industry Growth can 'Fly Back' to Benefit Las Vegas", UNLV Gaming Research and Review Journal, 16(1), 87-92.

Hofstede, G. (n.d.), Various Issues, available at: http://geerthofstede.com/japan.html.

Hudman, L.E. and Jackson, R.H. (2003). Geography of Travel and Tourism, Singapore: Thomson Learning.

Kim, J., Wei, S. and Ruys, H. (2003). "Segmenting the Market of West Australian Senior Tourists Using an Artificial Neural Network", Tourism Management, 24(1), 25-34.
Mak, J. (2004). Tourism and the Economy: Understanding the Economics of Tourism, Honolulu, HI: University of Hawai'i Press.

Oyabu, T., Sawada, A., Zhu, Z. and Ohuchi, A. (2008). "Current Condition of Tourism Exchange between Taiwan and Hokuriku District and its Promotive Measure", in Pineda, F.D. and Brebbia, C.A. (eds.), Sustainable Tourism III, Boston, MA: WIT Press, 73-84.

Sahashi, R. (2014). "Japan-Taiwan Relations since 2008: An Evolving Practical, Non-Strategic Partnership," in Cabestan, J.-P. and de Lisle, J. (eds.), Political Changes in Taiwan under Ma Ying-jeou: Partisan Conflict, Policy Choices, External Constraints and Security Challenges, Oxford and New York, NY: Routledge, 232-246.

Sani, R.M. and Mahasti, P. (2012). "Regenerating Regional Identity for Sustainable Tourism Development Case Study: Eslami Island, Iran", Procedia -Social and Behavioral Sciences, 35, 523-530.

Shih, S.-M. (2007). Visuality and Identity: Sinophone Articulations across the Pacific, Berkeley, CA: University of California Press.

van Rekom, J. and Go, F. (2006). "Cultural Identities in a Globalizing World: Conditions for Sustainability of Intercultural Tourism," in Burns, P.M. and Novelli, M. (eds.), Advances in Tourism Research, Oxford: Elsevier, 79-90. 